\title{
Real-time PCR assays for genotyping of Cryptococcus gattii in North America
}

\author{
Erin J Kelley ${ }^{1 *}$, Elizabeth M Driebe ${ }^{1}$, Kizee Etienne ${ }^{2}$, Mary E Brandt ${ }^{2}$, James M Schupp ${ }^{1}$, John D Gillece ${ }^{1}$, \\ Jesse S Trujillo ${ }^{1}$, Shawn R Lockhart ${ }^{2}$, Eszter Deak ${ }^{2,3}$, Paul S Keim ${ }^{1,4}$ and David M Engelthaler ${ }^{1}$
}

\begin{abstract}
Background: Cryptococcus gattii has been the cause of an ongoing outbreak starting in 1999 on Vancouver Island, British Columbia and spreading to mainland Canada and the US Pacific Northwest. In the course of the outbreak, C. gattii has been identified outside of its previously documented climate, habitat, and host disease. Genotyping of C. gattii is essential to understand the ecological and geographical expansion of this emerging pathogen.

Methods: We developed and validated a mismatch amplification mutation assay (MAMA) real-time PCR panel for genotyping C. gattii molecular types VGI-VGIV and VGII subtypes a,b,c. Subtype assays were designed based on whole-genome sequence of 20 C. gattii strains. Publically available multilocus sequence typing (MLST) data from a study of 202 strains was used for the molecular type (VGI-VGIV) assay design. All assays were validated across DNA from 112 strains of diverse international origin and sample types, including animal, environmental and human.

Results: Validation revealed each assay on the panel is 100\% sensitive, specific and concordant with MLST. The assay panel can detect down to 0.5 picograms of template DNA.

Conclusions: The (MAMA) real-time PCR panel for C. gattii accurately typed a collection of 112 diverse strains and demonstrated high sensitivity. This is a time and cost efficient method of genotyping C. gattii best suited for application in large-scale epidemiological studies.
\end{abstract}

Keywords: Cryptococcus gattii, Genotyping, Real-time PCR, Epidemiology

\section{Background}

Cryptococcosis, a potentially fatal fungal disease, has primarily been observed in immune-compromised individuals and mainly associated with Cryptococcus neoformans infection. It is now recognized that Cryptococcus gattii, once considered to be a variety of the Cryptococcus neoformans complex, is also capable of causing serious disease in immunocompetent individuals and animals [1,2]. C. gattii has been associated with a number of tree species in tropical and subtropical regions [3]. More recently, C. gattii caused an outbreak that began in 1999 on Vancouver Island, British Columbia and has spread to mainland Canada and the US Pacific Northwest [4]. This outbreak is unique in that it marked the identification of a Cryptococcus

\footnotetext{
*Correspondence: ekelley@tgen.org

${ }^{1}$ The Translational Genomics Research Institute, 3051 W. Shamrell Blvd. Ste. 106, Flagstaff, AZ 86001, USA

Full list of author information is available at the end of the article
}

species in a new climatic region (from tropical to temperate), habitat (from tropical trees to temperate; e.g., Douglas Fir) and host disease (from primary neurologic to primary pulmonary) $[3,5]$.

Recent epidemiological studies of C. gattii in North America provide insight into the organism's geographical expansion as well as the distribution of molecular genotypes [6-9]. C. gattii has been classically classified into four molecular types by MLST/AFLP, VGI/AFLP4, VGII/AFLP6, VGIII/AFLP5, VGIV/AFLP7 [3,5], with additional molecular types recently identified [10]. Interestingly, molecular types have been associated with significant differences in disease type [3,5], antifungal susceptibilities $[3,5,10]$, and severity and outcome $[3,5]$.

Contemporary methods for genotyping C. gattii are PCR-restriction fragment length polymorphism (PCRRFLP), amplified fragment length polymorphism (AFLP), multilocus microsatellite typing (MLMT), multilocus sequence typing (MLST), and most recent, matrix-assisted 
laser desorption ionization-time-of-flight mass spectrometry (MALDI-TOF MS) [11-14]. High resolution melting (HRM) is a method that has been used to identify the Cryptococcus neoformans-Cryptococcus gattii complex, though it has not been employed for genotyping within either species [15]. PCR-RFLP and AFLP require extensive lab work involving restriction enzyme digestion and gel electrophoresis [11]. Results are based on interpretation of gel electrophoresis profiles and as such, are not readily transferred or analyzed between laboratories. MLST, which requires DNA sequencing of seven housekeeping genes, is the preferred genotyping method for $C$. gattii and is easily transferrable between laboratories [16]. MLMT allows for finer genotype resolution than MLST and has high reproducibility between laboratories [14]. In some laboratories, real-time PCR is a preferable option to methods involving DNA sequencing (MLMT and MLST), which require either out-sourcing to a sequencing capable laboratory or investment in, and the maintenance of, an in-house instrument. Although MALDI-TOF MS shows promise as a new genotyping method, instrumentation is expensive and thus prohibitive for many public health laboratories. Conversely, real-time PCR instruments are becoming ubiquitous, easily maintained, and the use of unlabeled primers and no probe makes reagents inexpensive [17]. Therefore, real-time PCR is an accessible and increasing popular technology for widespread molecular epidemiological efforts.

Here, we present a panel of real-time PCR assays, based on mismatch amplification mutation assay (MAMA) methodology, for rapid and sensitive molecular genotyping of Cryptococcus gattii molecular types (VGI-VGIV) and the dominant North American VGII subtypes (VGIIa-c) $[18,19]$. MAMA, a form of allele-specific PCR (ASPCR), employs primers that are designed for SNP genotyping. We use known MLST sequences for the VGI-VGIV molecular type assay design and whole genome sequences of 20 strains to identify SNPs specific to each of the targeted VGII subtypes [9,20].

\section{Methods}

\section{SYBR MAMA design}

MAMA primers have an intentional penultimate mismatch nucleotide at the $3^{\prime}$ end; the ultimate base is always the SNP assay target and is a perfect match for the target SNP [18]. Mismatches decrease the efficiency of primer extension by Taq polymerase, such that if two mismatches are found together under the 3 ' end of the primer, the efficiency of the PCR is significantly reduced. However, if a single mismatch at the penultimate base is present, extension occurs from the $3^{\prime}$ matched base, and efficiency of the PCR remains relatively high. Costly fluorogenic oligonucleotide probes are not needed to discriminate SNPs with this method. This discriminatory design results in a cost-efficient, powerful and simple method of SNP genotyping $[17,21]$. Separate PCR reactions are performed with a MAMA primer specific for only one of the two target SNPs and with one universal primer for amplification from the alternate direction. Comparison of cycle threshold $(\mathrm{Ct})$ values will reveal which reaction is more efficient (has the smaller $\mathrm{Ct}$ value). The more efficient reaction corresponds to the SNP that is present in the sample.

\section{MAMA design for MLST groups VGI, VGII, VGIII, and VGIV} The MLST SYBR MAMA design was informed by MLST data collected for 202 C. gatii strains from a worldwide collection [20]. The MLST library included sequences from 77, 75, 26, and 24 isolates of the VGI, VGII, VGIII, VGIV molecular types, respectively. The gene encoding mannitol-1-phosphate dehydrogenase (MPD1) was selected as the best candidate for assay design based on its sequence conservation within each of the four molecular types that allowed for design of assay primers with a minimum number of degenerate bases. All 15 of the known MPD1 allele sequences were aligned with SeqMan Pro v.9.0.4 (DNASTAR, Madison, WI). SNPs specific for each of the molecular types were identified in the sequence alignment. MAMA primers were manually designed in Primer Express 3.0 (Life Technologies, Carlsbad, CA) software with optimal mismatches chosen as suggested by Li et. al. [19] (Table 1).

\section{MAMA design for VGlla, VGIlb, and VGllc subtypes}

Whole genome sequence typing (WGST) analysis of 20 C. gattii strains from a previous study revealed canonical SNPs specific for each of the VGII a, b and c subtypes ( $\mathrm{n}=2720,3547$, and 3819, respectively) [9]. In order to minimize interference of adjacent mutations with primer design, the genotype-specific SNPs were sorted according to nearest neighboring mismatch within the sequence alignment; in short, the SNPs with the most-conserved flanking regions were the top candidates for assay design. Sequence from the R265 strain reference genome [GenBank: CH408164] [2] surrounding the genotype-specific SNPs was used for assay design. SYBR MAMA primers were designed using the same criteria as previously described for the MLST MAMA (Table 1).

\section{Isolate selection}

Initially, assays were validated with genomic DNA extracted from 57 C. gattii strains of North American origin and some historical isolates. The panel of isolates including: 13 VGIIa, 4 VGIIb, and 24 VGIIc, and 8 each of VGI and VGIII, was analyzed using each of the assays (Table 2). All DNAs were genotyped by MLST prior to screening. Further validation of the assays was accomplished by employing a more diverse isolate collection of 55 strains including isolates of international origin; this 
Table 1 MAMA real-time PCR assay sequences and targets for genotyping C. gattii

\begin{tabular}{|c|c|c|c|c|c|c|}
\hline Genotype & Assay Name & $\begin{array}{l}\text { Gene } \\
\text { (SNP position) }\end{array}$ & $\begin{array}{l}\text { Base call } \\
\text { match/mismatch }\end{array}$ & Universal Primer sequence $5^{\prime}->3^{\prime}$ & Match MAMA Primer sequence $5^{\prime}->3^{\prime}$ & Mismatch MAMA Primer sequence $5^{\prime}->3^{\prime}$ \\
\hline VGI & VGI-MPD471 & MPD1 (471) & $\mathrm{G} / \mathrm{A}$ & AGACTGTCCCAATGTCAAGCTTTC & GCCTTGTATGTGGTAACACCAGTG & GWGCCTTGTATGTGGTAACACCAGTA \\
\hline VGII & VGII-MPD495 & MPD1 (495) & T/A & AGACTGTCCCAATGTCAAGCTTTC & ATTAACCTTAGTGTTGGAGACCTTGACT & AACCTTAGTGTTGGAGACCTTGACA \\
\hline VGlla & VGlla-45211 & hypothetical protein & $\mathrm{A} / \mathrm{C}$ & CCCAGCAACCTTGATCTGGA & AGCTGCTCTAAGAGACACATCATCA & AGCTGCTCTAAGAGACACATCATCC \\
\hline VGllb & VGllb-502129 & not annotated & $\mathrm{G} / \mathrm{A}$ & AATCGCTCGTCCTCATATGACA & GTAGGCGGTGGGATAAGGTG & GGTAGGCGGTGGGATAAGGTA \\
\hline VGIllc & VGIllc-257655 & non-coding region & $C / T$ & CGTTAATTGGTTGTTTGACAACCT & AGCAACTCACGCAGAAACAGAC & GAGCAACTCACGCAGAAACAGAT \\
\hline$\overline{\text { VGIIII }}$ & VGIII-MPD198 & MPD1 (198) & T/A & TGACATTGGGACAGTCTGCAAT & ACTGCTGCTTCTCCCGTTGT & CTGCTGCTTCTCCCGTTGA \\
\hline VGIV & VGIV-MPD423 & MPD1 (423) & $\mathrm{A} / \mathrm{C}$ & ACCCAGTCATTAACCTTAGTGTTGGA & CTCGTTCGTCAAYCACGTTAGA & TCGTTCGTCAAYCACGTTAGC \\
\hline
\end{tabular}


Table 2 C. gattii strains for initial assay validation

\begin{tabular}{|c|c|c|c|c|}
\hline Isolate ID & MLST & Year & Geographic origin & Source \\
\hline B7488 & VGl & 2009 & Oregon & Human \\
\hline B7496 & VGl & 2009 & Hawaii & Dolphin \\
\hline B8551 & VGl & 2010 & Oregon & Human \\
\hline B8852 & VGl & 2010 & Oregon & Human \\
\hline B8886 & VGl & 2010 & Oregon & Soil \\
\hline B8887 & VGl & 2010 & Oregon & Soil \\
\hline B8990 & VGl & 2010 & California & Human \\
\hline B9009 & VGl & 2011 & Washington & Human \\
\hline B6864 & VGlla & 2004 & Oregon & Human \\
\hline B7395 & VGlla & 2008 & Washington & Dog \\
\hline B7422 & VGlla & 2009 & Oregon & Cat \\
\hline B7436 & VGlla & 2009 & California & Alpaca \\
\hline B7467 & VGlla & 2009 & Oregon & Porpoise \\
\hline B8555 & VGlla & 2006 & Washington & Human \\
\hline B8577 & VGlla & 2009 & British Columbia & Soil \\
\hline B8793 & VGlla & 2010 & Oregon & Canine \\
\hline B8849 & VGlla & 2010 & Oregon & Environmental \\
\hline CA-1014 & VGlla & unknown & California & Human \\
\hline CBS-7750 & VGlla & 1990 & California & Environmental \\
\hline ICB-107 & VGlla & unknown & Brazil & Human \\
\hline $\mathrm{NIH}-444$ & VGlla & 1972 & Washington & Human \\
\hline B7394 & VGllb & 2008 & Washington & Cat \\
\hline B7735 & VGllb & 2009 & Oregon & Human \\
\hline B8554 & VGllb & 2010 & Oregon & Dog \\
\hline B8828 & VGllb & 2010 & Washington & Porpoise \\
\hline B6863 & VGIlc & 2005 & Oregon & Human \\
\hline B7390 & VGIll & 2008 & Idaho & Human \\
\hline B7432 & VGIllc & 2009 & Oregon & Human \\
\hline B7434 & VGIllc & 2008 & Oregon & Human \\
\hline B7466 & VGIllc & 2008 & Oregon & Cat \\
\hline B7491 & VGIlc & 2009 & Oregon & Human \\
\hline B7493 & VGIll & 2009 & Oregon & Sheep \\
\hline B7641 & VGIll & 2008 & Oregon & Cat \\
\hline B7737 & VGIllc & 2009 & Oregon & Human \\
\hline B7765 & VGIlc & 2009 & Oregon & Dog \\
\hline B8210 & VGIllc & 2008 & Oregon & Human \\
\hline B8214 & VGIllc & 2009 & Oregon & Human \\
\hline B8510 & VGIllc & 2009 & Oregon & Human \\
\hline B8549 & VGIll & unknown & Oregon & Human \\
\hline B8552 & VGIll & unknown & Oregon & Human \\
\hline B8571 & VGIllc & 2009 & Washington & Human \\
\hline B8788 & VGIll & 2010 & Oregon & Human \\
\hline B8798 & VGIlc & 2005 & Oregon & Human \\
\hline B8821 & VGIlc & 2010 & Oregon & Human \\
\hline B8825 & VGIllc & 2009 & Oregon & Human \\
\hline B8833 & VGIlc & 2010 & Oregon & Cat \\
\hline B8838 & VGIlc & 2010 & Washington & Human \\
\hline
\end{tabular}

Table 2 C. gattii strains for initial assay validation (Continued)

\begin{tabular}{lllll}
\hline B8843 & VGIIC & 2010 & Oregon & Human \\
\hline B8853 & VGIIC & 2010 & Oregon & Cat \\
\hline B7415 & VGIII & 2009 & California & Alpaca \\
\hline B7495 & VGIII & 2009 & California & Human \\
\hline B8212 & VGIII & 2007 & Oregon & Human \\
\hline B8260 & VGIII & 2009 & Washington & Cat \\
\hline B8262 & VGIII & 1992 & California & Human \\
\hline B8516/B8616 & VGIII & 2009 & Oregon & Cat \\
\hline B9143 & VGIII & 2011 & California & Human \\
\hline B9146 & VGIII & 2011 & California & Human \\
\hline
\end{tabular}

panel was comprised of 10 VGI, 10 VGIIa, 9 VGIIb, 8 VGIIc, 8 VGIII, and 10 VGIV molecular types (Table 3). The strains came from a variety of environmental, human and animal sources, including cats, a dog, an alpaca, a porpoise, a sheep and a cow.

\section{Isolate culturing and DNA extraction}

Isolates were grown on Yeast Peptone Glucose (YPD) agar plus $0.5 \% \mathrm{NaCl}$ at $37^{\circ} \mathrm{C}$ for 24 hours; and DNA was prepared using an UltraClean DNA Isolation Kit as described by the manufacturer, with some modifications (MO BIO Laboratories, Carlsbad, CA). Briefly, 0.5 grams of microbial cells were suspended in lysis solution in a MicroBead tube and heated to $65^{\circ} \mathrm{C}$ for 15 minutes to increase lysis efficiency. The MicroBead tube was then secured horizontally using the MO BIO vortex adapter tube holder (MO BIO Laboratories, Carlsbad, CA) and vortexed at maximum speed for 10 minutes; post cell lysis, microtubes were immediately placed on ice for 5 minutes. After the lysis steps, DNA extraction was completed per manufacturer's instructions. DNA was stored at $-20^{\circ} \mathrm{C}$.

\section{Real-time PCR}

Real-time PCR was performed on the ABI 7900HT realtime PCR System (Life Technologies, Carlsbad, CA). Reactions for both perfect match and mismatch primer sets were conducted in separate wells of a 384-well optical plate, and reactions for each primer set were run in triplicate. Reactions were $10 \mu \mathrm{L}$ total volume composed of 1X Platinum SYBR Green qPCR SuperMix-UDG with ROX (Invitrogen, Grand Island, NY), $200 \mathrm{nM}$ each of forward and reverse primers, and $1 \mu \mathrm{L}$ DNA extract (diluted 1:10). Reactions were incubated for $3 \mathrm{~min}$ at $50^{\circ} \mathrm{C}$ for UDG digest followed by $3 \mathrm{~min}$ at $95^{\circ} \mathrm{C}$ for Taq polymerase activation. PCR consisted of 45 cycles of $15 \mathrm{~s}$ at $95^{\circ} \mathrm{C}$ for denaturation followed by $1 \mathrm{~min}$ at $60^{\circ} \mathrm{C}$ annealing and extension. Dissociation of PCR product was performed for $15 \mathrm{sec}$ at $95^{\circ} \mathrm{C}, 15 \mathrm{sec}$ at $60^{\circ} \mathrm{C}$ and $15 \mathrm{sec}$ at $95^{\circ} \mathrm{C}$ as a quality assurance step to inspect reactions for primer-dimer. 
Table 3 C. gattii strains for additional assay validation

\begin{tabular}{|c|c|c|c|c|}
\hline Culture collection ID & Geographic origin & Sample type & MLST & Year of isolation \\
\hline B4501 & Australia & Human & VGl & unknown \\
\hline B4503 & Australia & Human & VGl & unknown \\
\hline B4504 & Australia & Human & VGl & unknown \\
\hline B4516 & Australia & Human & VGl & unknown \\
\hline B5765 & India & Environmental & VGl & unknown \\
\hline B9018 & California & Human & VGI & 2011 \\
\hline B9019 & New Mexico & Human & VGl & 2011 \\
\hline B9021 & Rhode Island & Human & VGl & 2011 \\
\hline B9142 & Georgia & Human & VGl & 2011 \\
\hline B9149 & California & Human & VGl & 2011 \\
\hline B8508 & Oregon & Human & VGlla & 2009 \\
\hline $\mathrm{B} 8512$ & Oregon & Alpaca & VGlla & 2009 \\
\hline B8558 & Washington & Human & VGlla & 2010 \\
\hline B8561 & Washington & Human & VGlla & 2010 \\
\hline B8563 & Washington & Human & VGlla & 2010 \\
\hline B8567 & Washington & Dog & VGlla & 2010 \\
\hline B8854 & Washington & Human & VGlla & 2010 \\
\hline B8889 & Oregon & Environmental & VGlla & 2010 \\
\hline B9077 & Washington & Environmental & VGlla & 2011 \\
\hline B9296 & British Columbia & Environmental & VGlla & 2011 \\
\hline B8211 & Oregon & Human & VGIllb & 2009 \\
\hline B8966 & Oregon & Horse & VGllb & 2010 \\
\hline B9076 & Washington & Environmental & VGllb & 2011 \\
\hline B9157 & Washington & Horse & VGIllb & 2011 \\
\hline B9170 & Washington & Porpoise & VGIIb & 2011 \\
\hline B9234 & Washington & Cat & VGllb & 2011 \\
\hline B9290 & British Columbia & Cat & VGIIb & 2011 \\
\hline B9241 & Oregon & Human & VGllb & 2011 \\
\hline B9428 & Washington & Cat & VGllb & 2012 \\
\hline B9159 & Washington & Sheep & VGIllc & 2011 \\
\hline B9227 & Oregon & Cat & VGllc & 2011 \\
\hline B9235 & Oregon & Human & VGIllc & 2011 \\
\hline B9244 & Oregon & Human & VGllc & 2011 \\
\hline B9245 & Oregon & Human & VGllc & 2011 \\
\hline B9295 & British Columbia & Environmental & VGllc & 2011 \\
\hline B9302 & Oregon & Environmental & VGIllc & 2011 \\
\hline B9374 & Oregon & Human & VGIllc & 2011 \\
\hline B8965 & New Mexico & Human & VGIII & 2010 \\
\hline B9148 & California & Human & VGIII & 2011 \\
\hline B9151 & Michigan & Human & VGIII & 2011 \\
\hline B9163 & New Mexico & Human & VGIII & 2011 \\
\hline B9237 & New Mexico & Cat & VGIII & 2011 \\
\hline B9372 & California & Cow & VGIII & 2011 \\
\hline B9422 & Oregon & Cat & VGIII & 2012 \\
\hline B9430 & Alaska & Cat & VGIII & 2012 \\
\hline B7238 & Botswana & Human & VGIV & 2005 \\
\hline B7240 & Botswana & Human & VGIV & 2005 \\
\hline
\end{tabular}


Table 3 C. gattii strains for additional assay validation (Continued)

\begin{tabular}{lllll}
\hline B7243 & Botswana & Human & VGIV & 2005 \\
\hline B7247 & Botswana & Human & VGIV & 2005 \\
\hline B7249 & Botswana & Human & VGIV & 2005 \\
\hline B7260 & Botswana & Human & VGIV & 2006 \\
\hline B7262 & Botswana & Human & VGIV & 2006 \\
\hline B7263 & Botswana & Human & VGIV \\
\hline B7264 & Botswana & Human & VGIV & 2006 \\
\hline B7265 & Botswana & Human & VGIV & 2006 \\
\hline
\end{tabular}

Dissociation curves were not used for isolate genotyping, rather to ensure amplification was specific for the targeted sequence and to preclude non-specific amplification associated with the ability of SYBR Green chemistry to bind any double-stranded DNA. Data were analyzed in Sequence Detection Systems 2.3 software (Life Technologies, Carlsbad, CA) for calculation of cycle threshold $(\mathrm{Ct})$ values and interpretation of dissociation curves.

For MAMA results, the perfect match primer set will amplify earlier and yield the lowest $\mathrm{Ct}$ value, corresponding to the SNP genotype of the isolate; secondary delayed amplification plots with a higher $\mathrm{Ct}$ value, if present, are due to mismatch priming (Figure 1). An algorithm for genotype calling was implemented to expedite data analysis. The delta $\mathrm{Ct}$ value was calculated by subtracting the match primer mean $\mathrm{Ct}$ from the mismatch primer mean $\mathrm{Ct}$. If the mismatch priming fails to yield a $\mathrm{Ct}$ value because it is beyond the instrument range, a $\mathrm{Ct}$ value $=40$ is assigned in order to calculate a $\Delta \mathrm{Ct}$.

$\Delta \mathrm{Ct}=($ mismatch mean $\mathrm{Ct})-($ perfect match mean $\mathrm{Ct})$
A negative $\Delta \mathrm{Ct}$ value indicates a mismatch allele, whereas a positive $\Delta \mathrm{Ct}$ indicates a match allele. A stringent threshold of $|\Delta \mathrm{Ct}| \geq 3.3$, approximately equivalent to one $\log _{10}$ difference in the dynamic range, was established to ensure accuracy of allele calls. If $|\Delta \mathrm{Ct}|<3.3$ is below the stringent threshold, this could result in an inaccurate genotype call. In this case, it is advisable to re-screen the sample across the failed assays.

Sensitivity and specificity of the assay panel were calculated as well as concordance with the known MLST type as determined by sequencing the MLST house keeping genes. Assay repeatability and reproducibility were tested by screening nine replicate reactions with the matching primer sets and DNA for each assay on three separate days. The lower limit of detection for each assay and its matching template pair was tested. Each matching template and assay pair was tested using six $\log _{10}$ serial dilutions of a single template DNA, starting with $0.5 \mathrm{ng} / \mu \mathrm{l}$. Template DNA was quantified in triplicate by NanoDrop 3300 fluorospectrometer (NanoDrop Technologies, Wilmington, DE) using Quant-iT PicoGreen dsDNA Reagent (Life Technologies, Carlsbad, CA), according to manufacturer's instructions.
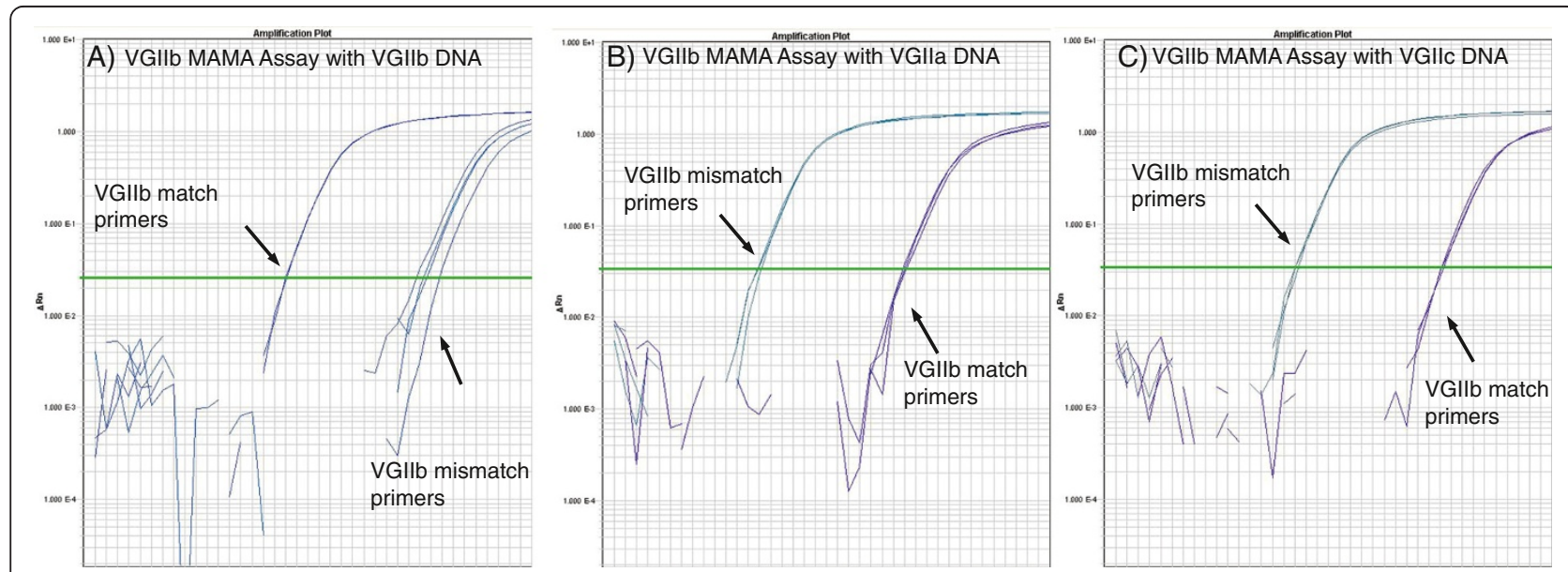

Figure 1 VGIlb MAMA plots with VGII DNA show the specificity of VGIlb MAMA for VGIlb DNA. (A) The VGIllb match primers amplify VGllb DNA efficiently and yield a lower Ct value than the VGllb mismatch primers, resulting in a VGllb genotype call. (B) The VGllb mismatch primers amplify VGlla DNA more efficiently than the VGIllb match primers, resulting in a non-VGllb genotype call. (C) VGllb mismatch primers amplify VGIllc DNA more efficiently than the VGllb match primers, again resulting in a non-VGllb genotype call. 
Table 4 MLST SYBR MAMA Ct values and genotype assignments for VGI-VGIV

\section{VGI_MPD471 VGII_MPD495}

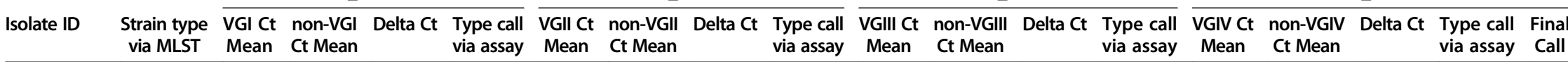

\begin{tabular}{|c|c|c|c|c|c|c|c|c|c|c|c|c|c|c|c|c|c|c|}
\hline B7488 & VGI & 17.0 & 29.0 & 11.9 & VGI & 37.4 & 17.7 & -19.7 & non-VGll & 28.4 & 14.9 & -13.5 & non-VGIII & 32.4 & 16.3 & -16.1 & non-VGIV & VGI \\
\hline B7496 & VGI & 18.2 & 28.0 & 9.8 & VGI & 35.3 & 19.0 & -16.3 & non-VGII & 24.5 & 16.4 & -8.1 & non-VGIII & 31.7 & 17.9 & -13.8 & non-VGIV & $\overline{\text { VGI }}$ \\
\hline B8551 & VGI & 17.3 & 29.6 & 12.3 & VGI & 36.2 & 17.9 & -18.3 & non-VGII & 28.7 & 15.3 & -13.4 & non-VGIII & 39.0 & 16.7 & -22.3 & non-VGIV & VGI \\
\hline B8852 & VGI & 21.1 & 30.9 & 9.8 & VGI & 36.5 & 21.9 & -14.6 & non-VGII & 27.8 & 19.1 & -8.8 & non-VGIII & 32.0 & 20.6 & -11.4 & non-VGIV & VGI \\
\hline B8886 & VGI & 18.9 & 29.2 & 10.3 & VGI & 38.1 & 19.3 & -18.8 & non-VGII & 26.7 & 16.4 & -10.3 & non-VGIII & 32.3 & 17.9 & -14.4 & non-VGIV & VGI \\
\hline B8887 & VGI & 15.9 & 28.3 & 12.4 & VGI & 23.6 & 15.5 & -8.1 & non-VGII & 33.6 & 16.2 & -17.4 & non-VGIII & 34.1 & 15.5 & -18.7 & non-VGIV & VGI \\
\hline B8990 & VGI & 18.8 & 30.9 & 12.1 & VGl & 37.2 & 20.1 & -17.1 & non-VGII & 31.3 & 16.9 & -14.3 & non-VGIII & 40.0 & 19.3 & -20.7 & non-VGIV & VGI \\
\hline B9009 & VGI & 21.6 & 31.0 & 9.4 & VGI & 36.5 & 23.1 & -13.4 & non-VGII & 28.6 & 19.4 & -9.2 & non-VGIII & 40.0 & 21.1 & -18.9 & non-VGIV & VGI \\
\hline B4501 & VGI & 16.1 & 26.7 & 10.6 & VGI & 30.5 & 18.1 & -12.4 & non-VGII & 30.6 & 17.3 & -13.3 & non-VGIII & 29.4 & 16.4 & -13.0 & non-VGIV & VGI \\
\hline B4503 & VGI & 15.9 & 27.2 & 11.2 & VGI & 32.7 & 18.6 & -14.1 & non-VGII & 33.8 & 17.9 & -15.9 & non-VGIII & 28.7 & 16.1 & -12.6 & non-VGIV & $\overline{V G I}$ \\
\hline B4504 & VGI & 15.6 & 27.2 & 11.5 & VGl & 33.1 & 18.1 & -15.1 & non-VGII & 33.9 & 17.4 & -16.4 & non-VGIII & 28.7 & 15.8 & -13.0 & non-VGIV & VGI \\
\hline B4516 & VGI & 15.3 & 26.8 & 11.5 & VGI & 31.5 & 17.6 & -13.9 & non-VGII & 33.4 & 16.8 & -16.6 & non-VGIII & 29.7 & 15.3 & -14.3 & non-VGIV & VGI \\
\hline B5765 & VGI & 17.2 & 28.0 & 10.8 & VGI & 32.8 & 19.7 & -13.0 & non-VGII & 34.4 & 19.2 & -15.2 & non-VGIII & 29.0 & 16.3 & -12.7 & non-VGIV & $\overline{V G I}$ \\
\hline B9018 & VGI & 17.7 & 30.0 & 12.3 & VGI & 34.6 & 17.9 & -16.7 & non-VGII & 31.8 & 18.6 & -13.2 & non-VGIII & 35.0 & 18.3 & -16.8 & non-VGIV & VGI \\
\hline B9019 & VGI & 16.9 & 26.1 & 9.2 & VGI & 35.4 & 16.7 & -18.7 & non-VGII & 34.9 & 16.7 & -18.2 & non-VGIII & 30.5 & 16.8 & -13.7 & non-VGIV & VGI \\
\hline B9021 & VGI & 21.4 & 32.9 & 11.5 & VGI & 33.4 & 19.9 & -13.5 & non-VGII & 32.7 & 20.5 & -12.2 & non-VGIII & 35.5 & 20.4 & -15.2 & non-VGIV & VGI \\
\hline B9142 & VGI & 16.0 & 26.3 & 10.3 & VGI & 27.8 & 15.9 & -11.9 & non-VGII & 32.7 & 16.5 & -16.2 & non-VGIII & 31.7 & 16.6 & -15.1 & non-VGIV & VGI \\
\hline B9149 & VGI & 17.7 & 26.8 & 9.1 & VGl & 28.5 & 17.5 & -11.0 & non-VGII & 28.5 & 18.2 & -10.3 & non-VGIII & 31.0 & 18.3 & -12.6 & non-VGIV & VGI \\
\hline B6864 & VGlla & 27.8 & 17.5 & -10.3 & non-VGl & 19.3 & 33.1 & 13.8 & VGII & 34.7 & 19.7 & -15.0 & non-VGIII & 40.0 & 16.1 & -23.9 & non-VGIV & VGII \\
\hline B7395 & VGlla & 28.9 & 18.8 & -10.1 & non-VGl & 21.3 & 32.6 & 11.3 & VGII & 40.0 & 19.2 & 19.2 & non-VGIII & 40.0 & 18.8 & -21.2 & non-VGIV & VGII \\
\hline B7422 & VGlla & 27.4 & 17.4 & -10.0 & non-VGl & 19.5 & 32.3 & 12.8 & VGII & 35.4 & 19.1 & -16.3 & non-VGIII & 40.0 & 15.6 & -24.4 & non-VGIV & VGII \\
\hline B7436 & VGlla & 27.8 & 17.9 & -9.9 & non-VGl & 20.7 & 35.4 & 14.7 & VGII & 36.5 & 16.9 & -19.6 & non-VGIII & 40.0 & 15.6 & -24.4 & non-VGIV & VGII \\
\hline B7467 & VGlla & 30.9 & 20.7 & -10.1 & non-VGl & 22.7 & 32.7 & 9.9 & VGII & 37.7 & 23.4 & -14.2 & non-VGIII & 40.0 & 19.1 & -20.9 & non-VGIV & VGII \\
\hline B8555 & VGlla & 27.9 & 17.7 & -10.2 & non-VGl & 19.7 & 32.1 & 12.4 & VGII & 34.6 & 20.8 & -13.8 & non-VGIII & 40.0 & 16.6 & -23.4 & non-VGIV & VGII \\
\hline B8577 & VGlla & 31.1 & 20.9 & -10.2 & non-VGl & 21.8 & 34.1 & 12.3 & VGII & 33.1 & 23.4 & -9.8 & non-VGIII & 40.0 & 19.8 & -20.2 & non-VGIV & VGII \\
\hline B8793 & VGlla & 27.4 & 17.4 & -10.0 & non-VGl & 18.9 & 32.6 & 13.7 & VGII & 39.0 & 24.9 & -14.1 & non-VGIII & 40.0 & 16.3 & -23.7 & non-VGIV & VGII \\
\hline B8849 & VGlla & 28.9 & 18.7 & -10.1 & non-VGl & 22.9 & 35.1 & 12.2 & VGII & 36.0 & 22.7 & -13.3 & non-VGIII & 40.0 & 18.4 & -21.6 & non-VGIV & VGII \\
\hline CA-1014 & VGlla & 20.4 & 11.6 & -8.8 & non-VGl & 13.6 & 32.4 & 18.9 & VGII & 31.1 & 12.8 & -18.3 & non-VGIII & 40.0 & 11.0 & -29.0 & non-VGIV & VGII \\
\hline CBS-7750 & VGlla & 27.2 & 17.3 & -9.9 & non-VGl & 18.8 & 33.1 & 14.3 & VGII & 38.0 & 25.5 & -12.5 & non-VGIII & 40.0 & 15.8 & -24.2 & non-VGIV & VGII \\
\hline ICB-107 & VGlla & 28.1 & 18.2 & -9.9 & non-VGl & 20.0 & 34.7 & 14.8 & VGII & 37.5 & 25.4 & -12.1 & non-VGIII & 40.0 & 15.6 & -24.4 & non-VGIV & VGII \\
\hline $\mathrm{NIH}-444$ & VGlla & 24.9 & 14.9 & -10.0 & non-VGl & 17.0 & 33.2 & 16.2 & VGII & 34.9 & 17.7 & -17.2 & non-VGIII & 40.0 & 13.3 & -26.7 & non-VGIV & VGII \\
\hline B8508 & VGlla & 23.7 & 14.8 & -8.9 & non-VGl & 17.4 & 30.4 & 13.0 & VGII & 34.5 & 16.2 & -18.2 & non-VGIII & 29.1 & 14.9 & -14.2 & non-VGIV & VGII \\
\hline B8512 & VGlla & 23.5 & 14.6 & -9.0 & non-VGl & 16.7 & 30.6 & 13.9 & VGII & 31.4 & 15.7 & -15.6 & non-VGIII & 29.7 & 14.8 & -14.9 & non-VGIV & VGII \\
\hline
\end{tabular}


Table 4 MLST SYBR MAMA Ct values and genotype assignments for VGI-VGIV (Continued)

\begin{tabular}{|c|c|c|c|c|c|c|c|c|c|c|c|c|c|c|c|c|c|c|}
\hline B8558 & VGlla & 22.5 & 13.7 & -8.8 & non-VGl & 15.9 & 29.9 & 14.0 & VGII & 30.6 & 14.9 & -15.7 & non-VGIII & 30.1 & 14.3 & -15.9 & non-VGIV & VGII \\
\hline B8561 & VGlla & 26.5 & 17.7 & -8.8 & non-VGl & 20.3 & 34.2 & 14.0 & VGII & 34.1 & 19.1 & -15.0 & non-VGIII & 33.2 & 22.2 & -11.0 & non-VGIV & VGII \\
\hline B8563 & VGlla & 24.4 & 16.0 & -8.4 & non-VGl & 18.4 & 32.8 & 14.4 & VGII & 32.8 & 20.4 & -12.4 & non-VGIII & 32.2 & 17.3 & -14.9 & non-VGIV & VGII \\
\hline B8567 & VGlla & 25.6 & 17.0 & -8.6 & non-VGl & 19.4 & 34.1 & 14.7 & VGII & 33.8 & 18.2 & -15.6 & non-VGIII & 35.1 & 16.8 & -18.2 & non-VGIV & VGII \\
\hline B8854 & VGlla & 24.7 & 15.8 & -8.9 & non-VGl & 18.1 & 32.7 & 14.6 & VGII & 33.0 & 17.1 & -15.9 & non-VGIII & 33.2 & 15.8 & -17.4 & non-VGIV & VGII \\
\hline B8889 & VGIla & 28.0 & 17.6 & -10.4 & non-VGl & 20.3 & 33.1 & 12.7 & VGII & 33.7 & 19.1 & -14.6 & non-VGIII & 32.4 & 17.5 & -15.0 & non-VGIV & VGII \\
\hline B9077 & VGlla & 33.6 & 17.8 & -15.9 & non-VGl & 15.4 & 28.6 & 13.2 & VGII & 40.0 & 18.6 & -21.5 & non-VGIII & 40.0 & 18.6 & -21.4 & non-VGIV & VGII \\
\hline B9296 & VGlla & 27.3 & 19.8 & -7.5 & non-VGl & 18.6 & 34.0 & 15.4 & VGII & 32.4 & 20.8 & -11.6 & non-VGIII & 34.9 & 19.2 & -15.7 & non-VGIV & VGII \\
\hline B7394 & VGllb & 31.9 & 22.5 & -9.5 & non-VGl & 23.5 & 33.5 & 10.0 & VGII & 33.7 & 19.3 & -14.4 & non-VGIII & 40.0 & 20.2 & -19.8 & non-VGIV & VGII \\
\hline B7735 & VGllb & 26.9 & 17.8 & -9.1 & non-VGl & 18.3 & 33.3 & 15.0 & VGII & 0.0 & 15.8 & 15.8 & non-VGIII & 40.0 & 15.4 & -24.6 & non-VGIV & VGII \\
\hline B8554 & VGllb & 28.8 & 18.3 & -10.5 & non-VGl & 20.8 & 32.2 & 11.3 & VGII & 35.5 & 22.0 & -13.4 & non-VGIII & 40.0 & 18.3 & -21.7 & non-VGIV & VGII \\
\hline B8828 & VGIIb & 28.8 & 18.5 & -10.3 & non-VGl & 20.7 & 32.7 & 11.9 & VGII & 35.9 & 19.2 & -16.7 & non-VGIII & 40.0 & 31.9 & -8.1 & non-VGIV & VGII \\
\hline B8211 & VGllb & 22.9 & 12.8 & -10.1 & non-VGl & 15.1 & 30.1 & 15.1 & VGII & 33.0 & 13.9 & -19.0 & non-VGIII & 33.8 & 12.9 & -21.0 & non-VGIV & VGII \\
\hline B8966 & VGllb & 24.6 & 15.5 & -9.0 & non-VGl & 17.3 & 25.9 & 8.6 & VGII & 29.3 & 15.6 & -13.7 & non-VGIII & 28.9 & 14.7 & -14.2 & non-VGIV & VGII \\
\hline B9076 & VGllb & 40.0 & 17.5 & -22.5 & non-VGl & 17.1 & 27.5 & 10.5 & VGII & 40.0 & 18.4 & -21.6 & non-VGIII & 30.6 & 18.0 & -12.6 & non-VGIV & VGII \\
\hline B9157 & VGllb & 25.4 & 15.3 & -10.2 & non-VGl & 17.6 & 29.4 & 11.9 & VGII & 31.2 & 16.1 & -15.1 & non-VGIII & 31.6 & 16.1 & -15.5 & non-VGIV & VGII \\
\hline B9170 & VGllb & 26.2 & 16.9 & -9.3 & non-VGl & 17.5 & 28.7 & 11.2 & VGII & 29.5 & 17.6 & -11.9 & non-VGIII & 31.1 & 17.7 & -13.4 & non-VGIV & VGII \\
\hline B9234 & VGllb & 24.7 & 15.0 & -9.6 & non-VGl & 15.4 & 30.3 & 14.9 & VGII & 30.2 & 15.7 & -14.5 & non-VGIII & 33.3 & 15.8 & -17.5 & non-VGIV & VGII \\
\hline B9290 & VGllb & 24.8 & 16.0 & -8.8 & non-VGl & 15.9 & 34.1 & 18.2 & VGII & 30.6 & 20.8 & -9.7 & non-VGIII & 33.2 & 16.6 & -16.6 & non-VGIV & VGII \\
\hline B9241 & VGllb & 23.4 & 13.2 & -10.3 & non-VGl & 15.5 & 28.0 & 12.5 & VGII & 30.0 & 13.9 & -16.0 & non-VGIII & 34.0 & 13.5 & -20.5 & non-VGIV & VGII \\
\hline B9428 & VGllb & 25.2 & 14.4 & -10.7 & non-VGl & 18.7 & 28.3 & 9.6 & VGII & 30.2 & 15.5 & -14.7 & non-VGIII & 34.1 & 15.0 & -19.1 & non-VGIV & VGII \\
\hline B6863 & VGIllc & 28.9 & 18.6 & -10.2 & non-VGl & 20.7 & 34.2 & 13.5 & VGII & 33.2 & 22.7 & -10.6 & non-VGIII & 40.0 & 18.1 & -21.9 & non-VGIV & VGII \\
\hline B7390 & VGIllc & 27.7 & 18.3 & -9.5 & non-VGl & 19.9 & 33.9 & 13.9 & VGII & 39.5 & 24.7 & -14.8 & non-VGIII & 40.0 & 16.9 & -23.1 & non-VGIV & VGII \\
\hline B7432 & VGIllc & 28.2 & 18.3 & -9.9 & non-VGl & 20.0 & 32.6 & 12.7 & VGII & 34.8 & 18.0 & -16.8 & non-VGIII & 40.0 & 17.2 & -22.8 & non-VGIV & VGII \\
\hline B7434 & VGIllc & 25.6 & 16.2 & -9.4 & non-VGl & 17.7 & 34.5 & 16.8 & VGII & 34.4 & 17.9 & -16.5 & non-VGIII & 40.0 & 13.8 & -26.2 & non-VGIV & VGII \\
\hline B7466 & VGIllc & 30.8 & 20.8 & -10.0 & non-VGl & 22.4 & 33.6 & 11.2 & VGII & 37.4 & 23.7 & -13.7 & non-VGIII & 40.0 & 19.5 & -20.5 & non-VGIV & VGII \\
\hline B7491 & VGIllc & 26.9 & 17.3 & -9.6 & non-VGl & 19.2 & 33.0 & 13.8 & VGII & 0.0 & 16.8 & 16.8 & non-VGIII & 40.0 & 16.7 & -23.3 & non-VGIV & VGII \\
\hline B7493 & VGIllc & 27.1 & 17.4 & -9.7 & non-VGl & 18.6 & 33.6 & 15.1 & VGII & 36.6 & 20.7 & -15.8 & non-VGIII & 40.0 & 16.1 & -23.9 & non-VGIV & VGII \\
\hline B7641 & VGIllc & 26.0 & 17.3 & -8.7 & non-VGl & 18.7 & 32.3 & 13.7 & VGII & 34.3 & 20.0 & -14.3 & non-VGIII & 40.0 & 15.6 & -24.4 & non-VGIV & VGII \\
\hline B7737 & VGIllc & 28.0 & 18.5 & -9.6 & non-VGl & 20.1 & 34.3 & 14.2 & VGII & 37.0 & 23.0 & -14.0 & non-VGIII & 40.0 & 18.0 & -22.0 & non-VGIV & VGII \\
\hline B7765 & VGIllc & 22.5 & 13.0 & -9.5 & non-VGl & 14.5 & 34.1 & 19.6 & VGII & 33.1 & 23.4 & -9.7 & non-VGIIII & 40.0 & 12.9 & -27.1 & non-VGIV & VGII \\
\hline B8210 & VGIllc & 27.8 & 18.1 & -9.7 & non-VGl & 19.6 & 33.3 & 13.7 & VGII & 33.0 & 19.4 & -13.5 & non-VGIII & 40.0 & 16.8 & -23.2 & non-VGIV & VGII \\
\hline B8214 & VGIllc & 27.1 & 17.7 & -9.5 & non-VGl & 19.8 & 34.9 & 15.1 & VGII & 34.1 & 20.1 & -14.0 & non-VGIII & 40.0 & 16.1 & -23.9 & non-VGIV & VGII \\
\hline B8510 & VGIllc & 26.8 & 17.6 & -9.2 & non-VGl & 18.8 & 33.2 & 14.5 & VGII & 35.2 & 19.1 & -16.1 & non-VGIII & 40.0 & 15.6 & -24.4 & non-VGIV & VGII \\
\hline B8549 & VGIllc & 26.8 & 16.2 & -10.6 & non-VGl & 18.7 & 33.5 & 14.8 & VGII & 37.4 & 20.5 & -16.9 & non-VGIII & 40.0 & 29.6 & -10.4 & non-VGIV & VGII \\
\hline
\end{tabular}


Table 4 MLST SYBR MAMA Ct values and genotype assignments for VGI-VGIV (Continued)

\begin{tabular}{|c|c|c|c|c|c|c|c|c|c|c|c|c|c|c|c|c|c|c|}
\hline B8552 & VGIllc & 27.1 & 17.0 & -10.1 & non-VGl & 18.6 & 33.2 & 14.6 & VGII & 34.3 & 19.7 & -14.6 & non-VGIII & 40.0 & 16.6 & -23.4 & non-VGIV & VGII \\
\hline B8571 & VGIlc & 28.8 & 19.4 & -9.4 & non-VGl & 21.5 & 33.4 & 11.9 & VGII & 34.5 & 22.8 & -11.8 & non-VGIII & 40.0 & 19.5 & -20.5 & non-VGIV & $\overline{\text { VGII }}$ \\
\hline B8788 & VGIllc & 26.0 & 16.0 & -10.0 & non-VGl & 18.5 & 29.5 & 11.0 & VGII & 38.0 & 20.4 & -17.6 & non-VGIII & 40.0 & 16.6 & -23.4 & non-VGIV & VGII \\
\hline B8798 & VGIllc & 36.0 & 24.7 & -11.4 & non-VGl & 26.5 & 33.3 & 6.8 & VGII & 37.2 & 19.2 & -18.0 & non-VGIII & 40.0 & 22.5 & -17.5 & non-VGIV & VGII \\
\hline B8821 & VGIllc & 30.5 & 20.5 & -10.0 & non-VGl & 22.3 & 33.0 & 10.7 & VGII & 37.0 & 29.0 & -8.0 & non-VGIII & 40.0 & 18.7 & -21.3 & non-VGIV & VGII \\
\hline B8825 & VGIllc & 27.4 & 17.8 & -9.6 & non-VGl & 19.6 & 33.7 & 14.1 & VGII & 36.0 & 20.5 & -15.5 & non-VGIII & 40.0 & 17.5 & -22.5 & non-VGIV & VGII \\
\hline B8833 & VGIllc & 29.2 & 20.7 & -8.6 & non-VGl & 19.5 & 33.4 & 13.9 & VGII & 35.4 & 19.6 & -15.8 & non-VGIII & 40.0 & 15.5 & -24.5 & non-VGIV & VGII \\
\hline B8838 & VGIllc & 29.2 & 19.1 & -10.1 & non-VGl & 21.5 & 32.8 & 11.3 & VGII & 32.9 & 22.3 & -10.6 & non-VGIII & 40.0 & 18.5 & -21.5 & non-VGIV & VGII \\
\hline B8843 & VGIllc & 29.5 & 19.4 & -10.1 & non-VGl & 21.5 & 33.7 & 12.2 & VGII & 37.5 & 22.1 & -15.4 & non-VGIII & 40.0 & 19.1 & -20.9 & non-VGIV & VGII \\
\hline B8853 & VGIlc & 33.3 & 23.1 & -10.2 & non-VGl & 24.8 & 33.7 & 8.9 & VGII & 34.2 & 27.8 & -6.4 & non-VGIII & 40.0 & 21.5 & -18.5 & non-VGIV & VGII \\
\hline B9159 & VGIIC & 29.6 & 17.5 & -12.1 & non-VGl & 19.1 & 29.9 & 10.7 & VGII & 40.0 & 26.0 & -14.0 & non-VGIII & 40.0 & 18.0 & -22.0 & non-VGIV & $\overline{\text { VGII }}$ \\
\hline B9227 & VGIIC & 24.4 & 15.3 & -9.1 & non-VGl & 15.5 & 28.1 & 12.6 & VGII & 27.9 & 16.1 & -11.9 & non-VGIII & 31.0 & 16.3 & -14.7 & non-VGIV & VGII \\
\hline B9235 & VGIllc & 24.6 & 15.1 & -9.5 & non-VGl & 15.3 & 28.9 & 13.7 & VGII & 29.2 & 16.4 & -12.7 & non-VGIII & 31.2 & 15.9 & -15.3 & non-VGIV & VGII \\
\hline B9244 & VGIllc & 27.3 & 18.4 & -8.9 & non-VGl & 18.5 & 31.8 & 13.3 & VGII & 28.2 & 21.0 & -7.2 & non-VGIII & 30.6 & 18.8 & -11.8 & non-VGIV & VGII \\
\hline B9245 & VGIIC & 26.8 & 17.9 & -8.9 & non-VGl & 18.0 & 33.5 & 15.5 & VGII & 31.2 & 19.3 & -11.9 & non-VGIII & 34.2 & 18.5 & -15.6 & non-VGIV & VGII \\
\hline B9295 & VGllc & 28.6 & 19.5 & -9.1 & non-VGl & 19.9 & 40.0 & 20.1 & VGII & 33.6 & 25.5 & -8.1 & non-VGIII & 34.4 & 20.3 & -14.2 & non-VGIV & VGII \\
\hline B9302 & VGIllc & 24.6 & 14.1 & -10.5 & non-VGl & 16.9 & 26.7 & 9.8 & VGII & 28.8 & 15.1 & -13.7 & non-VGIII & 31.5 & 14.1 & -17.3 & non-VGIV & $\overline{\text { VGII }}$ \\
\hline B9374 & VGllc & 24.8 & 14.2 & -10.6 & non-VGl & 18.2 & 27.3 & 9.1 & VGII & 29.1 & 15.2 & -13.9 & non-VGIII & 32.8 & 14.4 & -18.4 & non-VGIV & VGII \\
\hline B7415 & VGIII & 26.8 & 15.9 & -10.9 & non-VGl & 35.0 & 17.7 & -17.3 & non-VGII & 12.4 & 27.1 & 14.7 & VGIII & 30.9 & 15.9 & -15.0 & non-VGIV & VGIII \\
\hline B7495 & VGIII & 28.1 & 18.0 & -10.1 & non-VGl & 36.1 & 18.8 & -17.3 & non-VGII & 14.1 & 30.1 & 16.0 & VGIII & 31.8 & 17.6 & -14.2 & non-VGIV & VGIII \\
\hline B8212 & VGIII & 26.0 & 15.7 & -10.3 & non-VGl & 35.3 & 17.0 & -18.3 & non-VGII & 12.4 & 28.5 & 16.1 & VGIII & 32.5 & 15.6 & -16.9 & non-VGIV & VGIII \\
\hline B8260 & VGIII & 29.6 & 19.6 & -10.0 & non-VGl & 36.7 & 20.8 & -15.9 & non-VGII & 15.9 & 30.7 & 14.8 & VGIII & 36.0 & 19.1 & -16.9 & non-VGIV & VGIII \\
\hline B8262 & VGIII & 27.2 & 17.2 & -10.0 & non-VGl & 33.8 & 18.3 & -15.5 & non-VGll & 13.5 & 30.0 & 16.4 & VGIII & 40.0 & 16.9 & -23.1 & non-VGIV & VGIII \\
\hline B8516/B8616 & VGIII & 28.4 & 18.5 & -9.9 & non-VGl & 37.8 & 19.5 & -18.3 & non-VGII & 14.6 & 29.1 & 14.5 & VGIII & 31.8 & 18.0 & -13.8 & non-VGIV & VGIII \\
\hline B9143 & VGIII & 28.6 & 18.3 & -10.3 & non-VGl & 38.3 & 19.6 & -18.7 & non-VGll & 14.5 & 30.2 & 15.7 & VGIII & 33.3 & 18.0 & -15.3 & non-VGIV & VGIII \\
\hline B9146 & VGIII & 30.3 & 19.5 & -10.8 & non-VGl & 38.5 & 21.2 & -17.3 & non-VGII & 15.8 & 30.1 & 14.3 & VGIII & 31.2 & 19.3 & -11.9 & non-VGIV & VGIII \\
\hline B8965 & VGIII & 26.2 & 16.8 & -9.4 & non-VGl & 30.6 & 17.1 & -13.5 & non-VGII & 16.1 & 30.6 & 14.5 & VGIII & 35.0 & 17.4 & -17.6 & non-VGIV & VGIII \\
\hline B9148 & VGIII & 26.0 & 16.6 & -9.4 & non-VGl & 31.0 & 16.6 & -14.4 & non-VGII & 15.9 & 30.6 & 14.7 & VGIII & 32.8 & 17.4 & -15.4 & non-VGIV & VGIII \\
\hline B9151 & VGIII & 25.7 & 16.5 & -9.3 & non-VGl & 30.7 & 16.2 & -14.4 & non-VGII & 15.4 & 30.3 & 14.9 & VGIII & 34.9 & 18.0 & -17.0 & non-VGIV & VGIII \\
\hline B9163 & VGIII & 26.9 & 17.5 & -9.4 & non-VGl & 29.8 & 17.3 & -12.5 & non-VGII & 16.9 & 29.7 & 12.8 & VGIII & 33.4 & 18.0 & -15.4 & non-VGIV & VGIII \\
\hline B9237 & VGIII & 26.7 & 17.9 & -8.9 & non-VGl & 31.6 & 17.4 & -14.2 & non-VGII & 17.3 & 35.0 & 17.7 & VGIII & 38.1 & 19.3 & -18.9 & non-VGIV & VGIII \\
\hline B9372 & VGIII & 23.5 & 12.7 & -10.9 & non-VGl & 29.3 & 13.1 & -16.1 & non-VGII & 14.8 & 27.4 & 12.6 & VGIII & 32.6 & 13.0 & -19.6 & non-VGIV & VGIII \\
\hline B9422 & VGIII & 23.9 & 12.8 & -11.1 & non-VGl & 28.9 & 12.9 & -15.9 & non-VGII & 14.6 & 26.8 & 12.2 & VGIII & 33.0 & 13.3 & -19.7 & non-VGIV & VGIII \\
\hline B9430 & VGIII & 23.5 & 12.9 & -10.6 & non-VGl & 30.1 & 13.4 & -16.8 & non-VGII & 15.1 & 28.5 & 13.4 & VGIII & 35.5 & 13.4 & -22.0 & non-VGIV & VGIII \\
\hline B7238 & VGIV & 25.2 & 16.4 & -8.8 & non-VGl & 33.2 & 18.5 & -14.7 & non-VGIl & 34.6 & 17.9 & -16.7 & non-VGIII & 16.3 & 27.4 & 11.1 & VGIV & VGIV \\
\hline
\end{tabular}


Table 4 MLST SYBR MAMA Ct values and genotype assignments for VGI-VGIV (Continued)

\begin{tabular}{|c|c|c|c|c|c|c|c|c|c|c|c|c|c|c|c|c|c|c|}
\hline B7240 & VGIV & 25.8 & 17.1 & -8.8 & non-VGl & 33.9 & 19.5 & -14.5 & non-VGII & 34.2 & 18.5 & -15.7 & non-VGIII & 17.0 & 28.8 & 11.8 & VGIV & VGIV \\
\hline B7243 & VGIV & 26.1 & 17.3 & -8.8 & non-VGl & 32.0 & 19.6 & -12.4 & non-VG\|l & 32.3 & 18.7 & -13.6 & non-VGIII & 16.8 & 27.1 & 10.2 & VGIV & VGIV \\
\hline B7247 & VGIV & 25.6 & 16.5 & -9.1 & non-VGl & 33.4 & 19.2 & -14.2 & non-VGII & 32.0 & 18.1 & -13.9 & non-VGIII & 16.3 & 28.4 & 12.1 & VGIV & $\overline{\text { VGIV }}$ \\
\hline B7249 & VGIV & 23.4 & 14.8 & -8.6 & non-VGl & 31.6 & 16.7 & -14.9 & non-VGII & 32.6 & 16.0 & -16.6 & non-VGIII & 14.5 & 31.1 & 16.5 & VGIV & VGIV \\
\hline B7260 & VGIV & 26.0 & 16.5 & -9.4 & non-VGl & 30.9 & 18.0 & -13.0 & non-VGII & 34.2 & 17.4 & -16.8 & non-VGIII & 15.7 & 27.0 & 11.2 & VGIV & VGIV \\
\hline B7262 & VGIV & 26.3 & 16.8 & -9.5 & non-VGl & 31.4 & 18.7 & -12.7 & non-VGII & 33.4 & 18.0 & -15.4 & non-VGIII & 15.8 & 27.5 & 11.6 & VGIV & VGIV \\
\hline B7263 & VGIV & 24.5 & 15.7 & -8.9 & non-VGl & 33.1 & 17.9 & -15.3 & non-VGII & 37.3 & 17.0 & -20.3 & non-VGIII & 15.8 & 28.0 & 12.2 & VGIV & VGIV \\
\hline B7264 & VGIV & 24.4 & 15.0 & -9.4 & non-VGl & 31.2 & 16.9 & -14.3 & non-VGII & 30.6 & 16.0 & -14.6 & non-VGIII & 14.8 & 26.8 & 12.0 & VGIV & $\overline{\text { VGIV }}$ \\
\hline B7265 & VGIV & 27.5 & 17.3 & -10.2 & non-VGl & 34.1 & 19.6 & -14.5 & non-VGII & 32.1 & 18.8 & -13.3 & non-VGIII & 16.9 & 28.8 & 11.9 & VGIV & VGIV \\
\hline
\end{tabular}


Table 5 VGII subtyping SYBR MAMA Ct values and genotype assignments for VGlla,b,c

\begin{tabular}{|c|c|c|c|c|c|c|c|c|c|c|c|c|c|c|}
\hline \multirow[b]{2}{*}{ Isolate ID } & \multirow[b]{2}{*}{$\begin{array}{c}\text { Strain type } \\
\text { via MLST }\end{array}$} & \multicolumn{4}{|c|}{ VGlla_Assay_45211 } & \multicolumn{4}{|c|}{ VGllb_Assay_502129 } & \multicolumn{5}{|c|}{ VGllc_Assay_257655 } \\
\hline & & $\begin{array}{l}\text { VGlla Ct } \\
\text { Mean }\end{array}$ & $\begin{array}{l}\text { non-VGlla } \\
\text { Ct Mean }\end{array}$ & Delta Ct & $\begin{array}{l}\text { Type call } \\
\text { via assay }\end{array}$ & $\begin{array}{l}\text { VGllb Ct } \\
\text { Mean }\end{array}$ & $\begin{array}{l}\text { non-VGIlb } \\
\text { Ct Mean }\end{array}$ & Delta Ct & $\begin{array}{l}\text { Type call } \\
\text { via assay }\end{array}$ & $\begin{array}{l}\text { VGllc Ct } \\
\text { Mean }\end{array}$ & $\begin{array}{l}\text { non-VGllc } \\
\text { Ct Mean }\end{array}$ & Delta Ct & $\begin{array}{l}\text { Type call } \\
\text { via assay }\end{array}$ & Final Call \\
\hline B6864 & VGlla & 17.2 & 30.5 & 13.3 & VGlla & 31.0 & 17.5 & -13.5 & non-VGllb & 40.0 & 27.8 & -12.2 & non-VGllc & VGlla \\
\hline B7395 & VGlla & 19.8 & 33.5 & 13.7 & VGlla & 33.1 & 20.3 & -12.9 & non-VGllb & 40.0 & 30.6 & -9.4 & non-VGllc & VGIla \\
\hline B7422 & VGlla & 18.3 & 33.6 & 15.4 & VGlla & 26.4 & 17.6 & -8.8 & non-VGllb & 39.2 & 28.6 & -10.6 & non-VGllc & VGIla \\
\hline B7436 & VGlla & 18.6 & 31.7 & 13.1 & VGlla & 30.1 & 17.0 & -13.2 & non-VGllb & 38.0 & 29.1 & -8.9 & non-VGllc & VGIla \\
\hline B7467 & VGlla & 20.5 & 37.3 & 16.8 & VGlla & 35.1 & 20.3 & -14.7 & non-VGllb & 40.0 & 30.9 & -9.1 & non-VGllc & VGlla \\
\hline B8555 & VGlla & 17.1 & 31.2 & 14.1 & VGlla & 30.3 & 17.5 & -12.8 & non-VGllb & 40.0 & 27.7 & -12.3 & non-VGIlc & VGIla \\
\hline B8577 & VGlla & 20.8 & 36.8 & 16.0 & VGlla & 32.8 & 20.8 & -12.1 & non-VGllb & 40.0 & 31.4 & -8.6 & non-VGIlc & VGIla \\
\hline B8793 & VGlla & 15.1 & 29.8 & 14.7 & VGlla & 30.7 & 18.6 & -12.1 & non-VGllb & 40.0 & 29.8 & -10.2 & non-VGllc & VGIla \\
\hline B8849 & VGlla & 19.8 & 34.4 & 14.6 & VGlla & 33.6 & 20.2 & -13.4 & non-VGllb & 40.0 & 30.6 & -9.4 & non-VGIlc & VGIla \\
\hline CA-1014 & VGlla & 13.1 & 27.3 & 14.2 & VGlla & 27.0 & 14.0 & -13.0 & non-VGllb & 34.9 & 24.2 & -10.7 & non-VGIlc & VGIla \\
\hline CBS-7750 & VGlla & 21.8 & 32.2 & 10.4 & VGlla & 33.4 & 21.5 & -11.9 & non-VGIlb & 40.0 & 34.1 & -5.9 & non-VGllc & VGIla \\
\hline ICB-107 & VGlla & 21.8 & 33.6 & 11.8 & VGlla & 33.2 & 21.2 & -12.0 & non-VGllb & 40.0 & 33.8 & -6.2 & non-VGllc & VGIla \\
\hline $\mathrm{NIH}-444$ & VGlla & 14.8 & 27.3 & 12.5 & VGlla & 28.5 & 15.3 & -13.1 & non-VGIllb & 36.1 & 25.7 & -10.3 & non-VGllc & VGIla \\
\hline B8508 & VGlla & 17.0 & 27.8 & 10.8 & VGlla & 26.5 & 17.3 & -9.2 & non-VGllb & 31.7 & 22.7 & -9.1 & non-VGIlc & VGIla \\
\hline B8512 & VGIla & 17.6 & 28.1 & 10.4 & VGIla & 26.3 & 18.0 & -8.3 & non-VGIlb & 33.2 & 24.2 & -9.0 & non-VGIlc & VGIla \\
\hline B8558 & VGlla & 16.3 & 24.8 & 8.5 & VGlla & 27.3 & 15.3 & -12.0 & non-VGllb & 29.4 & 20.0 & -9.4 & non-VGIlc & VGIla \\
\hline B8561 & VGlla & 15.8 & 27.5 & 11.8 & VGlla & 25.0 & 16.9 & -8.1 & non-VGllb & 33.4 & 23.2 & -10.2 & non-VGIlc & VGIla \\
\hline B8563 & VGlla & 14.5 & 27.3 & 12.8 & VGlla & 23.9 & 15.6 & -8.3 & non-VGIlb & 31.7 & 21.7 & -10.0 & non-VGllc & VGlla \\
\hline B8567 & VGlla & 15.0 & 36.2 & 21.2 & VGlla & 24.5 & 16.0 & -8.5 & non-VGllb & 31.8 & 22.2 & -9.5 & non-VGllc & VGIla \\
\hline B8854 & VGlla & 14.7 & 26.7 & 12.0 & VGIla & 24.1 & 15.1 & -9.0 & non-VGllb & 31.4 & 22.2 & -9.2 & non-VGIlc & VGIla \\
\hline B8889 & VGlla & 17.0 & 28.1 & 11.0 & VGlla & 25.9 & 17.3 & -8.7 & non-VGllb & 33.2 & 23.8 & -9.4 & non-VGllc & VGIla \\
\hline B9077 & VGlla & 16.7 & 27.8 & 11.1 & VGlla & 25.6 & 16.7 & -9.0 & non-VGllb & 32.9 & 24.4 & -8.4 & non-VGllc & VGIla \\
\hline B9296 & VGlla & 17.0 & 27.5 & 10.5 & VGlla & 25.5 & 17.3 & -8.2 & non-VGIllb & 32.9 & 24.8 & -8.1 & non-VGllc & VGIla \\
\hline B7394 & VGllb & 40.0 & 19.0 & -21.0 & non-VGlla & 17.3 & 29.6 & 12.3 & VGllb & 40.0 & 29.0 & -11.0 & non-VGllc & VGIlb \\
\hline B7735 & VGIIb & 31.0 & 18.3 & -12.8 & non-VGlla & 18.7 & 31.3 & 12.6 & VGIIb & 38.1 & 28.9 & -9.3 & non-VGIlc & VGIlb \\
\hline B8554 & VGllb & 32.9 & 21.2 & -11.7 & non-VGlla & 22.2 & 35.0 & 12.8 & VGllb & 40.0 & 30.4 & -9.6 & non-VGllc & VGIIb \\
\hline B8828 & VGllb & 31.9 & 21.1 & -10.8 & non-VGlla & 19.9 & 35.1 & 15.2 & VGllb & 40.0 & 30.5 & -9.5 & non-VGllc & VGIlb \\
\hline B8211 & VGllb & 27.8 & 16.9 & -10.9 & non-VGlla & 17.4 & 28.8 & 11.4 & VGllb & 32.3 & 22.3 & -10.0 & non-VGIlc & VGIllb \\
\hline B8966 & VGIllb & 26.2 & 14.7 & -11.5 & non-VGlla & 16.3 & 24.1 & 7.9 & VGllb & 31.8 & 23.2 & -8.6 & non-VGllc & VGIIb \\
\hline B9076 & VGIllb & 30.0 & 18.8 & -11.2 & non-VGlla & 19.7 & 30.9 & 11.4 & VGIllb & 39.1 & 27.0 & -12.1 & non-VGIlc & VGIlb \\
\hline B9157 & VGllb & 29.1 & 16.6 & -12.4 & non-VGlla & 15.4 & 23.8 & 8.5 & VGllb & 30.3 & 21.3 & -9.0 & non-VGllc & VGIlb \\
\hline B9170 & VGllb & 26.6 & 15.4 & -11.2 & non-VGlla & 16.9 & 24.8 & 7.9 & VGllb & 31.0 & 22.7 & -8.3 & non-VGllc & VGIlb \\
\hline B9234 & VGllb & 26.1 & 13.9 & -12.2 & non-VGlla & 15.3 & 23.8 & 8.5 & VGllb & 30.2 & 21.2 & -9.1 & non-VGllc & VGllb \\
\hline
\end{tabular}


Table 5 VGII subtyping SYBR MAMA Ct values and genotype assignments for VGlla,b,c (Continued)

\begin{tabular}{|c|c|c|c|c|c|c|c|c|c|c|c|c|c|c|}
\hline B9290 & VGllb & 26.1 & 13.8 & -12.3 & non-VGlla & 15.1 & 24.5 & 9.5 & VGllb & 30.6 & 21.2 & -9.5 & non-VGllc & VGIllb \\
\hline B9241 & VGllb & 26.7 & 20.2 & -6.5 & non-VGlla & 14.5 & 24.0 & 9.4 & VGllb & 30.5 & 21.4 & -9.1 & non-VGllc & VGIllb \\
\hline B9428 & VGllb & 27.5 & 14.8 & -12.6 & non-VGlla & 16.0 & 24.3 & 8.2 & VGllb & 32.0 & 22.4 & -9.6 & non-VGllc & VGIllb \\
\hline B6863 & VGllc & 31.9 & 20.3 & -11.5 & non-VGlla & 33.4 & 20.2 & -13.2 & non-VGllb & 27.5 & 40.0 & 12.5 & VGllc & VGllc \\
\hline B7390 & VGIllc & 32.7 & 18.9 & -13.8 & non-VGlla & 31.1 & 17.9 & -13.2 & non-VGllb & 25.9 & 40.0 & 14.1 & VGIllc & VGIlc \\
\hline B7432 & VGIllc & 40.0 & 18.5 & -21.5 & non-VGlla & 30.7 & 17.6 & -13.1 & non-VGllb & 25.7 & 40.0 & 14.3 & VGIllc & VGIlc \\
\hline B7434 & VGIllc & 27.5 & 15.5 & -12.0 & non-VGlla & 28.5 & 15.4 & -13.1 & non-VGllb & 23.3 & 40.0 & 16.7 & VGllc & VGIlc \\
\hline B7466 & VGIllc & 31.7 & 20.8 & -10.9 & non-VGlla & 33.5 & 20.6 & -12.8 & non-VGllb & 28.1 & 40.0 & 11.9 & VGIllc & VGIlc \\
\hline B7491 & VGIllc & 28.7 & 17.4 & -11.2 & non-VGlla & 30.4 & 16.9 & -13.5 & non-VGllb & 24.0 & 40.0 & 16.0 & VGIllc & VGIlc \\
\hline B7493 & VGIllc & 28.8 & 18.3 & -10.6 & non-VGlla & 31.1 & 18.0 & -13.1 & non-VGllb & 25.5 & 40.0 & 14.5 & VGIllc & VGIlc \\
\hline B7641 & VGIllc & 29.2 & 17.2 & -12.0 & non-VGlla & 30.0 & 17.2 & -12.8 & non-VGllb & 24.5 & 40.0 & 15.5 & VGIllc & VGIlc \\
\hline B7737 & VGIllc & 32.6 & 20.1 & -12.5 & non-VGlla & 30.8 & 20.5 & -10.4 & non-VGllb & 28.4 & 40.0 & 11.6 & VGIllc & VGIlc \\
\hline B7765 & VGIlc & 32.2 & 19.3 & -12.8 & non-VGlla & 32.3 & 18.9 & -13.3 & non-VGllb & 27.5 & 40.0 & 12.5 & VGIlc & VGIlc \\
\hline B8210 & VGIllc & 29.7 & 17.6 & -12.0 & non-VGlla & 30.1 & 17.4 & -12.7 & non-VGllb & 25.9 & 40.0 & 14.1 & VGIllc & VGIlc \\
\hline B8214 & VGIllc & 30.1 & 17.5 & -12.5 & non-VGlla & 30.9 & 17.5 & -13.4 & non-VGllb & 26.1 & 40.0 & 13.9 & VGIlc & VGIlc \\
\hline B8510 & VGIllc & 29.6 & 17.5 & -12.0 & non-VGlla & 31.0 & 17.3 & -13.7 & non-VGllb & 24.5 & 40.0 & 15.5 & VGIllc & VGIlc \\
\hline B8549 & VGIllc & 29.9 & 17.7 & -12.1 & non-VGlla & 31.0 & 17.8 & -13.2 & non-VGllb & 24.8 & 40.0 & 15.2 & VGIllc & VGIlc \\
\hline B8552 & VGIllc & 29.2 & 17.1 & -12.0 & non-VGlla & 30.3 & 17.2 & -13.1 & non-VGIllb & 24.4 & 40.0 & 15.6 & VGIllc & VGIlc \\
\hline B8571 & VGIllc & 33.0 & 20.3 & -12.7 & non-VGlla & 32.6 & 20.2 & -12.5 & non-VGIlb & 28.1 & 40.0 & 11.9 & VGIllc & VGIlc \\
\hline B8788 & VGIllc & 29.1 & 17.3 & -11.7 & non-VGlla & 30.0 & 17.2 & -12.8 & non-VGllb & 25.0 & 40.0 & 15.0 & VGIllc & VGIlc \\
\hline B8798 & VGIllc & 36.5 & 22.8 & -13.7 & non-VGlla & 34.5 & 22.2 & -12.3 & non-VGllb & 31.0 & 40.0 & 9.0 & VGllc & VGllc \\
\hline B8821 & VGIllc & 37.7 & 24.5 & -13.2 & non-VGlla & 37.1 & 24.4 & -12.7 & non-VGllb & 33.0 & 40.0 & 7.0 & VGIllc & VGIlc \\
\hline B8825 & VGllc & 29.6 & 17.7 & -11.9 & non-VGlla & 30.6 & 17.7 & -12.9 & non-VGllb & 25.8 & 40.0 & 14.2 & VGIlc & VGIlc \\
\hline B8833 & VGIllc & 29.0 & 17.0 & -12.0 & non-VGlla & 30.1 & 17.0 & -13.1 & non-VGllb & 25.2 & 40.0 & 14.8 & VGIllc & VGIlc \\
\hline B8838 & VGIllc & 32.0 & 19.5 & -12.5 & non-VGlla & 32.9 & 19.3 & -13.7 & non-VGIllb & 28.7 & 40.0 & 11.3 & VGllc & VGIlc \\
\hline B8843 & VGIllc & 32.4 & 19.9 & -12.5 & non-VGlla & 33.0 & 19.5 & -13.5 & non-VGIllb & 28.6 & 40.0 & 11.4 & VGIllc & VGIlc \\
\hline B8853 & VGIllc & 32.8 & 21.5 & -11.3 & non-VGlla & 36.0 & 23.4 & -12.6 & non-VGIllb & 33.1 & 40.0 & 6.9 & VGllc & VGIlc \\
\hline B9159 & VGIllc & 27.4 & 20.3 & -7.1 & non-VGlla & 25.8 & 16.7 & -9.1 & non-VGllb & 20.5 & 34.5 & 14.0 & VGllc & VGIlc \\
\hline B9227 & VGIllc & 25.6 & 13.6 & -12.0 & non-VGlla & 23.9 & 14.9 & -9.0 & non-VGllb & 18.0 & 31.5 & 13.4 & VGIllc & VGIlc \\
\hline B9235 & VGIllc & 25.9 & 13.7 & -12.1 & non-VGlla & 24.1 & 14.9 & -9.2 & non-VGllb & 18.4 & 32.4 & 14.0 & VGIllc & VGIlc \\
\hline B9244 & VGIllc & 27.2 & 19.1 & -8.1 & non-VGlla & 26.2 & 16.9 & -9.2 & non-VGllb & 20.2 & 32.5 & 12.3 & VGIllc & VGIlc \\
\hline B9245 & VGIllc & 28.4 & 22.9 & -5.5 & non-VGlla & 25.2 & 17.4 & -7.8 & non-VGllb & 20.7 & 34.5 & 13.8 & VGIllc & VGIlc \\
\hline B9295 & VGIllc & 21.0 & 17.1 & -3.8 & non-VGlla & 26.0 & 19.6 & -6.4 & non-VGllb & 22.1 & 28.1 & 5.9 & VGIll & VGIlc \\
\hline B9302 & VGIllc & 26.7 & 15.6 & -11.1 & non-VGlla & 23.7 & 15.4 & -8.3 & non-VGIlb & 19.4 & 34.3 & 15.0 & VGllc & VGIlc \\
\hline B9374 & VGIllc & 27.4 & 21.6 & -5.8 & non-VGlla & 24.0 & 15.3 & -8.7 & non-VGllb & 19.4 & 33.4 & 14.0 & VGIlc & VGIIc \\
\hline
\end{tabular}


Real-time PCR reactions were performed in triplicate for each dilution.

\section{Results}

Initial validation revealed the assay panel was $100 \%$ sensitive; each assay appropriately identified the known isolate genotypes. The $\Delta \mathrm{Ct}$ values for our validation panel confirmed the stringent threshold $\Delta \mathrm{Ct}=3.3$ sufficient to discriminate the genotypes. In addition, the assay panel was $100 \%$ specific; no cross reactivity occurred between assays and non-matching genotypes. Further validation of the assay panel with additional strains revealed $100 \%$ sensitivity and specificity. A total of 112 strains were screened across the MLST assay panel and 100\% sensitivity and specificity was observed (Table 4). A total of 68 previously genotyped strains were screened across the VGII subtyping assay panel with $100 \%$ sensitivity and specificity (Table 5). The assay coefficients of variation ranged from $0.22 \%$ to $4.33 \%$ indicating high assay repeatability and reproducibility within and between runs (Table 6). The assays were designed for genotyping of DNA from known C. gattii isolates, and are not validated for application to clinical specimens; they were able to detect DNA concentrations as low as $0.5 \mathrm{pg} / \mu \mathrm{l}$ (Table 7 ).

\section{Discussion}

C. gattii is an emerging pathogen in the US Pacific Northwest and British Columbia. Molecular and epidemiological investigations revealed the Vancouver Island, BC outbreak was attributed to a novel and seemingly hypervirulent VGIIa genotype [7,20,22]; moreover, the recent PNW outbreak was attributed to an additional novel genotype, VGIIc [23]. These apparent new genotypes (VGIIa and VGIIc), are responsible for greater than $90 \%$ of C. gattii infections in the BC/PNW region [7]. Given the increased virulence, varying antifungal susceptibilities and clinical outcomes caused by these genotypes, as compared to other C. gattii genotypes, it will be useful to conduct regular genotyping of C. gattii isolates for both clinical and epidemiological response purposes $[5,7,9,16]$.

Table 6 Interassay and Intraassay for MLST and Subtyping MAMA

\begin{tabular}{lll}
\hline Assay & interrun CV (\%) & intrarun CV (\%) \\
\hline VGI & 4.33 & 1.56 \\
\hline VGII & 2.35 & 0.22 \\
\hline VGIII & 0.43 & 0.60 \\
\hline VGIV & 1.37 & 1.08 \\
\hline VGlla & 0.22 & 0.50 \\
\hline VGIlb & 1.27 & 0.92 \\
\hline VGIlC & 1.61 & 0.32 \\
\hline
\end{tabular}

Table 7 Lower limit dynamic range for MLST and subtyping MAMA primer sets

\begin{tabular}{lll}
\hline Primer set tested & Limit $(\mathbf{p g})$ & Median $\mathbf{C t}$ \\
\hline VGI & 0.5 & 31.7 \\
\hline non-VGI & 0.5 & 31.1 \\
\hline VGII & 0.5 & 29.5 \\
\hline non-VGII & 0.5 & 28.7 \\
\hline VGIII & 0.5 & 28.5 \\
\hline non-VGIII & 0.5 & 29.9 \\
\hline VGIV & 0.5 & 33.7 \\
\hline non-VGIV & 0.5 & 33.2 \\
\hline VGIla & 0.5 & 30.2 \\
\hline non-VGIla & 0.5 & 31.2 \\
\hline VGIIb & 0.5 & 30.1 \\
\hline non-VGIlb & 0.5 & 28.5 \\
\hline VGIlc & 0.5 & 37.4 \\
\hline non-VGIlc & 0.05 & 39.4 \\
\hline
\end{tabular}

We have developed a MAMA real-time PCR panel for cost-efficient and rapid genotyping of $C$. gattii molecular types (I-IV) and VGII subtypes (a-c) as a means to better understand genotype distribution of C. gattii in North America. To validate the assays, we screened DNA from a diverse North American and international isolate collection of C. gattii isolates from human, environmental, and animal sources. All DNA had been previously typed by MLST. The assay panel performed with $100 \%$ sensitivity and specificity and was $100 \%$ concordant with MLST results. The VGII subtype specific assays may be more pertinent to the North American public health and medical communities; the molecular type (I-IV) specific assays will be useful for both North American and global genotyping. The assay is designed for screening in a cost-effective, stepwise manner. The molecular type-specific assays should be performed first on all isolates. In North America, the VGIV assay can be withheld for the first screen, as isolates of this molecular type have not yet been isolated from North America. For those North American isolates that are VGII by molecular type, the subtype-specific assays should be performed for typing VGIIa, VGIIb, or VGIIc. As we further our understanding of $C$. gattii populations around the world and their genotype-phenotype relationships, additional subtype specific assays can be similarly developed for local and global research purposes.

\section{Conclusions}

These PCR-based assays are an affordable, efficient, and sensitive means of genotyping $C$. gattii isolates. Both the assay methods and results can be easily transferred among laboratories. Assay results are based on real-time PCR cycle threshold values and are therefore objective and 
straightforward for local analysis. The assay panel presented here is a useful tool for conducting large-scale molecular epidemiological studies by public health and research laboratories.

\section{Ethics statement}

This study does not involve subjects or materials that would require approval by an ethics committee.

\begin{abstract}
Abbreviations
MAMA: Mismatch amplification mutation assay; MLST: Multilocus sequence typing; PCR-RFLP: PCR-restriction fragment length polymorphism; AFLP: Amplified fragment length polymorphism; MLMT: Multilocus microsatellite typing; HRM: High resolution melting; MALDI-TOF MS: Matrix-assisted laser desorption ionization-time-of-flight mass spectrometry; ASPCR: Allele-specific PCR; SNP: Single nucleotide polymorphism; Ct: Cycle threshold; MPD1: Mannitol-1-phosphate dehydrogenase; WGST: Whole genome sequence typing.
\end{abstract}

\section{Competing interests}

The authors declare that they have no competing interests.

\section{Authors' contributions}

EK designed the assays, assisted with assay validation, data analysis and drafted the manuscript. EMD participated in the design and coordination of the study, data analysis and assisted with drafting the manuscript. KE performed assay validation and data analysis and assisted with drafting the manuscript. MB was involved in the study conception, design and coordination. JS and JG assisted with data analysis for study design. JT performed assay validation and assay data analysis. SL and ED assisted with study conception, design and coordination and manuscript review. PK assisted with study design, coordination and manuscript review. DE assisted with study conception, design, coordination, and drafting of the manuscript. All authors read and approved the final manuscript.

\section{Acknowledgements}

The findings and conclusions of this article are those of the authors and do not necessarily represent the views of the Centers for Disease Control and Prevention.

The authors wish to thank the members of the Cryptococcus gattii Public Health Working Group for submission of many of the isolates used in this study. This work was supported by funds from the National Institutes of Health: R21Al098059.

\section{Author details}

'The Translational Genomics Research Institute, 3051 W. Shamrell Blvd. Ste. 106, Flagstaff, AZ 86001, USA. ${ }^{2}$ Centers for Disease Control and Prevention, Atlanta, GA, USA. ${ }^{3}$ Department of Pathology and Laboratory Medicine, David Geffen School of Medicine at UCLA, Los Angeles, CA, USA. ${ }^{4}$ Center for Microbial Genetics and Genomics, Northern Arizona University, Flagstaff, AZ, USA.

Received: 17 December 2013 Accepted: 6 May 2014

Published: 13 May 2014

\section{References}

1. Bovers M, Hagen F, Boekhout T: Diversity of the Cryptococcus neoformans-Cryptococcus gattii species complex. Rev Iberoam Micol 2008, 25(1):S4-S12.

2. D'Souza CA, Kronstad JW, Taylor G, Warren R, Yuen M, Hu G, Jung WH, Sham A, Kidd SE, Tangen K, Lee N, Zeilmaker T, Sawkins J, McVicker G, Shah S, Gnerre S, Griggs A, Zeng Q, Bartlett K, Li W, Wang X, Heitman J, Stajich JE, Fraser JA, Meyer W, Carter D, Schein J, Krzywinski M, Kwon-Chung K, Varma A, et al: Genome variation in Cryptococcus gattii, an emerging pathogen of immunocompetent hosts. MBio 2011, 2:e00342-10.

3. Lockhart SR, labal N, Bolden CB, DeBess EE, Marsden-Haug N, Worhle R, Thakur R, Harris JR: Epidemiologic cutoff values for triazole drugs in Cryptococcus gattii: correlation of molecular type and in vitro susceptibility. Diagn Microbiol Infect Dis 2012, 73(2):144-148.
4. Stephen CSL, Black W, Fyfe M, Raverty S: Multispecies outbreak of cryptococcosis on southern Vancouver Island, British Columbia. Can Vet J 2002, 43(10):792-794.

5. Iqbal N, DeBess EE, Wohrle R, Sun B, Nett RJ, Ahlquist AM, Chiller T, Lockhart SR: Correlation of genotype and in vitro susceptibilities of Cryptococcus gattii strains from the Pacific Northwest of the United States. J Clin Microbiol 2010, 48(2):539-544.

6. Byrnes EJ 3rd, Bildfell RJ, Frank SA, Mitchell TG, Marr KA, Heitman J: Molecular evidence that the range of the Vancouver Island outbreak of Cryptococcus gattii infection has expanded into the Pacific Northwest in the United States. J Infect Dis 2009, 199(7):1081-1086.

7. Byrnes EJ 3rd, Li W, Lewit Y, Ma H, Voelz K, Ren P, Carter DA, Chaturvedi V, Bildfell RJ, May RC, Heitman J: Emergence and pathogenicity of highly virulent Cryptococcus gattii genotypes in the northwest United States. PLoS Pathog 2010, 6(4):e1000850.

8. Walraven CJ, Gerstein W, Hardison SE, Wormley F, Lockhart SR, Harris JR, Fothergill A, Wickes B, Gober-Wilcox J, Massie L, Ku TS, Firacative C, Meyer W, Lee SA: Fatal disseminated Cryptococcus gattii infection in New Mexico. PLoS One 2011, 6(12):e28625.

9. Gillece JD, Schupp JM, Balajee SA, Harris J, Pearson T, Yan Y, Keim P, DeBess E, Marsden-Haug N, Wohrle R, Engelthaler DM, Lockhart SR: Whole genome sequence analysis of Cryptococcus gattii from the Pacific Northwest Reveals unexpected diversity. PLoS One 2011, 6(12):e28550.

10. Hagen F, Illnait-Zaragozi MT, Bartlett KH, Swinne D, Geertsen E, Klaassen CH, Boekhout T, Meis JF: In vitro antifungal susceptibilities and amplified fragment length polymorphism genotyping of a worldwide collection of 350 clinical, veterinary, and environmental Cryptococcus gattii isolates. Antimicrob Agents Chemother 2010, 54(12):5139-5145.

11. Sidrim JJ, Costa AK, Cordeiro RA, Brilhante RS, Moura FE, Castelo-Branco DS, Neto MP, Rocha MF: Molecular methods for the diagnosis and characterization of cryptococcus: a review. Can J Microbiol 2010, 56(6):445-458.

12. Firacative $C T L$, Meyer W: MALDI-TOF MS enables the rapid identification of the major molecular types within the Cryptococcus neoformans/C. Gattii species complex. PLoS One 2012, 7(5):e37566.

13. Posteraro B, Vella A, Cogliati M, De Carolis E, Florio AR, Posteraro P, Sanguinetti M, Tortorano AM: Matrix-assisted laser desorption ionization-time of flight mass spectrometry-based method for discrimination between molecular types of Cryptococcus neoformans and Cryptococcus gattii. I Clin Microbiol 2012, 50(7):2472-2476.

14. Hanafy A, Kaocharoen S, Jover-Botella A, Katsu M, lida S, Kogure T, Gonoi T, Mikami Y, Meyer W: Multilocus microsatellite typing for Cryptococcus neoformans var. grubii. Med Mycol 2008, 46(7):685-696.

15. Gago S, Zaragoza O, Cuesta I, Rodriguez-Tudela JL, Cuenca-Estrella M, Buitrago MJ: High-resolution melting analysis for identification of the Cryptococcus neoformans-Cryptococcus gattii complex. J Clin Microbiol 2011, 49(10):3663-3666.

16. Meyer W, Aanensen DM, Boekhout T, Cogliati M, Diaz MR, Esposto MC Fisher M, Gilgado F, Hagen F, Kaocharoen S, Litvintseva AP, Mitchell TG, Simwami SP, Trilles L, Viviani MA, Kwon-Chung J: Consensus multi-locus sequence typing scheme for Cryptococcus neoformans and Cryptococcus gattii. Med Mycol 2009, 47(6):561-570.

17. Birdsell DN, Pearson T, Price EP, Hornstra HM, Nera RD, Stone N, Gruendike J, Kaufman EL, Pettus AH, Hurbon AN, Buchhagen JL, Harms NJ, Chanturia G, Gyuranecz M, Wagner DM, Keim PS: Melt analysis of mismatch amplification mutation assays (Melt-MAMA): a functional study of a cost-effective SNP genotyping assay in bacterial models. PLoS One 2012, 7(3):e32866.

18. Cha RS, Zarbl H, Keohavong P, Thilly WG: Mismatch amplification mutation assay (MAMA): application to the C-H-ras gene. Genome Res 1992, 2(1):14-20.

19. Li B, Kadura I, Fu D-J, Watson DE: Genotyping with TaqMAMA. Genomics 2004, 83(2):311-320.

20. Fraser JA, Giles SS, Wenink EC, Geunes-Boyer SG, Wright JR, Diezmann S, Allen A, Stajich JE, Dietrich FS, Perfect JR, Heitman J: Same-sex mating and the origin of the Vancouver Island Cryptococcus gattii outbreak. Nature 2005, 437(7063):1360-1364.

21. Liu CM, Driebe EM, Schupp J, Kelley E, Nguyen JT, McSharry JJ, Weng Q, Engelthaler DM, Keim PS: Rapid quantification of single-nucleotide mutations in mixed influenza A viral populations using allele-specific mixture analysis. J Virol Methods 2010, 163(1):109-115.

22. Kidd SE, Hagen F, Tscharke RL, Huynh M, Bartlett KH, Fyfe M, Macdougall L, Boekhout T, Kwon-Chung K, Meyer W: A rare genotype of Cryptococcus 
gattii caused the cryptococcosis outbreak on Vancouver Island (British Columbia, Canada). Proc Natl Acad Sci U S A 2004, 101(49):17258-17263.

23. Silva DC, Martins MA, Szeszs MW, Bonfietti LX, Matos D, Melhem MS:

Susceptibility to antifungal agents and genotypes of Brazilian clinical and environmental Cryptococcus gattii strains. Diagn Microbiol Infect Dis 2012, 72(4):332-339.

doi:10.1186/1471-2180-14-125

Cite this article as: Kelley et al:: Real-time PCR assays for genotyping of Cryptococcus gattii in North America. BMC Microbiology 2014 14:125.

\section{Submit your next manuscript to BioMed Central and take full advantage of:}

- Convenient online submission

- Thorough peer review

- No space constraints or color figure charges

- Immediate publication on acceptance

- Inclusion in PubMed, CAS, Scopus and Google Scholar

- Research which is freely available for redistribution 